\title{
Influence of a fat overload on lipogenic regulators in metabolic syndrome patients
}

\author{
Maria Dolores Mayas ${ }^{1,2}$, Maria Isabel Queipo-Ortuño ${ }^{1,3}$, Mercedes Clemente-Postigo ${ }^{2}$, Manuel Macias², \\ Rajaa El Bekay $^{2}$, Francisco Jose Tinahones ${ }^{1,4 *}$ and Fernando Cardona ${ }^{1,2}$ \\ ${ }^{1}$ CIBER Fisiopatologia de la Obesidad y la Nutricion, Spain \\ ${ }^{2}$ Laboratorio de Investigacion del Hospital Virgen de la Victoria de Malaga (Fundacion IMABIS), Malaga, Spain \\ ${ }^{3}$ Fundacion IMABIS, Malaga, Spain \\ ${ }^{4}$ Servicio de Endocrinologia y Nutricion del Hospital Virgen de la Victoria de Malaga, Malaga, Spain
}

(Received 24 May 2010 - Revised 20 September 2010 - Accepted 24 September 2010 - First published online 30 November 2010 )

\begin{abstract}
Several epidemiological studies have related an increase of lipids in the postprandial state to an individual risk for the development of CVD, possibly due to the increased plasma levels of TAG and fatty acids (FA) through enzymes of FA metabolism. The interaction between nutrition and the human genome determines gene expression and metabolic response. The aim of the present study was to evaluate the influence of a fat overload on the gene mRNA levels of lipogenic regulators in peripheral blood mononuclear cells (PBMC) from patients with the metabolic syndrome. The study included twenty-one patients with criteria for the metabolic syndrome who underwent a fat overload. Measurements were made before and after the fat overload of anthropometric and biochemical variables and also the gene mRNA levels of lipogenic factors. The main results were that the fat overload led to an increased mRNA levels of sterol regulatory element binding protein-1 (SREBP1), retinoid X receptor $\alpha(R X R \alpha)$ and liver X receptor $\alpha(L X R \alpha)$ in PBMC, and this increase was associated with the FA synthase $(F A S N)$ mRNA levels. We also found that TAG levels correlated with $F A S N$ mRNA levels. In addition, there was a positive correlation of SREBP1 with $R X R \alpha$ and of $L X R \alpha$ with the plasma lipoperoxide concentration. The fat overload led to an increase in regulators of lipogenesis in PBMC from patients with the metabolic syndrome.
\end{abstract}

Key words: Genetic expression: Postprandial hypertriacylglycerolaemia: Lipogenic genes

Several epidemiological studies have shown that elevated lipid levels in the postprandial state pose an individual risk for the development of coronary artery disease ${ }^{(1,2)}$. Clinical studies have also shown that both the concentration and duration of postprandial lipidaemia play a role in the development and progression of atherosclerosis $^{(3,4)}$. All cells regulate gene expression in response to changes in the external environment. Nutrients can have a direct effect, interacting with transcription factors to regulate gene expression. This interaction between nutrients and gene response could be the key factor in the events that take place in the tissues where these nutrients are metabolised, since diet affects genes involved in lipid metabolism at the peripheral cell level. Experimental models have shown the lipid sensor response at the cellular level and its consequences on metabolism ${ }^{(5)}$, but in vivo mechanism of action in a multicellular organism, such as humans, is unknown. Fatty acid (FA) regulation of gene transcription seems to be due to the activity or abundance of at least four families of transcription factors: $P P A R$, liver $\mathrm{X}$ receptor $(L X R)$, hepatic nuclear factor $4 \alpha$ and sterol regulatory element binding protein (SREBP). Except for SREBP, all these factors belong to the steroid and thyroid hormone nuclear receptor family. These genes regulate several metabolic pathways, from inflammatory and oxidative stress pathways to lipogenic and lipid metabolism pathways. In fact, the increase in the rate of lipogenesis after a meal is interesting because this may be a key factor influencing the atherogenicity of the postprandial state ${ }^{(6)}$. SREBP are members of the basic helix-loop-helix family of transcription factors, which have been associated with lipogenesis, adipocyte development and cholesterol homeostasis, and they transcriptionally activate a cascade of enzymes required for endogenous cholesterol, FA, TAG and

Abbreviations: $C_{\mathrm{t}}$, threshold cycle; FA, fatty acid; $F A S N$, FA synthase; $L X R$, liver X receptor; PBMC, peripheral blood mononuclear cell; $R X R$, retinoid X receptor; $S C D$, stearoyl-coenzyme A desaturase; $S R E B P$, sterol regulatory element binding protein.

*Corresponding author: F. J. Tinahones, fax +34 951924651, email fernandocardonadiaz@gmail.com 
phospholipid synthesis ${ }^{(7,8)}$. They enhance the expression of multiple lipogenic genes such as FA synthase $(F A S N)^{(9)}$.

$L X R$ belongs to a family of nuclear receptors, which bind to the regulatory region of target genes and, upon ligand binding, regulate their transcription. Studies performed during the last decade have suggested that $L X R$ are 'cholesterol sensors' which, in response to excess cholesterol, stimulate their transport to the liver and biliary excretion. Therefore, stimulation of $L X R$ is a potentially useful therapeutic option for patients with dyslipidaemia ${ }^{(10)}$.

PUFA of the $n-3$ and $n-6$ family, such as arachidonic acid, EPA, DHA and linoleic acid, are competitive antagonists of the interaction between $L X R$ and its ligands ${ }^{(11)}$. $L X R$ agonists markedly stimulate FA synthesis (lipogenesis) in hepatocytes. This effect is partially mediated by the increased expression of SREBP1, which subsequently binds to the sterol response element within the promoter region of genes encoding numerous lipogenic enzymes ${ }^{(12)}$.

Retinoid $\mathrm{X}$ receptor $(R X R)$ is a nuclear receptor, which can modulate gene transcription by forming either homodimers or heterodimers with several other nuclear receptors, for example $L X R$ and $P P A R$. In fact, to activate its target genes such as $S R E B P, L X R$ has to be associated to form a heterodimer with $R X R$, and some studies have shown that $R X R$ can play a role in the control of TAG levels by activating the $L X R$ target gene of lipogenesis ${ }^{(13)}$

The objective of the present study was to determine the effect of a fat overload on the expression of nuclear sensors or genes related to lipid metabolism in peripheral cells and their association with serum lipids.

\section{Experimental methods}

\section{Study subjects}

The study included twenty-one patients (fifteen men and six women) with criteria for the metabolic syndrome, as defined by the Adult Treatment Panel III criteria(14), and with a normal oral glucose tolerance test. All the participants underwent a $60 \mathrm{~g}$ fat overload with a commercial preparation $\left(\right.$ Supracal $^{\mathbb{C}}$ ). Only water was permitted during the process, and no physical exercise was undertaken. The commercial preparation of $125 \mathrm{ml}$ contains $60 \mathrm{~g}$ fat: $12 \mathrm{~g}$ are SFA, $35.35 \mathrm{~g}$ are MUFA and $12.75 \mathrm{~g}$ are PUFA. Each $100 \mathrm{ml}$ contains less than $1 \mathrm{~g}$ lauric acid and $1 \mathrm{~g}$ myristic acid, $4.8 \mathrm{~g}$ palmitic acid, $1.4 \mathrm{~g}$ stearic acid, $27.7 \mathrm{~g}$ oleic acid, $9.6 \mathrm{~g}$ linoleic acid, $1.4 \mathrm{~g}$ behenic acid and $0.5 \mathrm{~g}$ lignoceric acid. The preparation contains no proteins or carbohydrates. The present study was conducted according to the guidelines laid down in the Declaration of Helsinki, and all procedures involving human subjects were approved by the Hospital ethics committee. Written informed consent was obtained from all subjects.

\section{Study design}

Before the fat overload, the participants' age as well as their height and weight to calculate their BMI was recorded. Also, waist and hip circumferences were measured with a soft tape midway between the lowest rib and the iliac crest to calculate the waist:hip ratio. In addition, blood samples were collected before and 3 and $4 \mathrm{~h}$ after the overload; serum and plasma were separated in aliquots within $30 \mathrm{~min}$ of extraction and immediately frozen at $-80^{\circ} \mathrm{C}$. The same procedure was followed with the peripheral blood mononuclear cells (PBMC), which were isolated from anticoagulant-treated blood by Ficoll standard density gradient centrifugation. Briefly, an equal volume of blood and PBS was mixed, and then this was layered onto Ficoll (the same volume as blood or PBS). After centrifugation ( $1800 \mathrm{rpm}, 30 \mathrm{~min}, 18^{\circ} \mathrm{C}$; brake off), a white layer created under the plasma layer was aspirated, where PBMC were situated. Then, these PBMC were washed twice with PBS ( $1400 \mathrm{rpm}, 10 \mathrm{~min}, 18^{\circ} \mathrm{C}$; brake off) and finally were resuspended with RNAlater.

\section{Methods}

Biochemical variables were glucose, cholesterol, TAG, apo $\mathrm{AI}$ and apo B, all measured in a dimension autoanalyser (Dade Behring, Deerfield, IL, USA) in duplicate. Serum insulin concentration was quantified by an immunoradiometric assay (BioSource International, Camarillo, CA, USA). NEFA were measured in duplicate by standard enzymatic methods (Wako Chemicals, Richmond, VA, USA) ${ }^{(15)}$.

Lipid peroxidation products (malondialdehyde + 4-hydroxyalkenals), GSSG, GSH and total glutathione $($ GSSG + GSH) levels were estimated using reagents purchased from Oxis International (Portland, OR, USA). Additionally, to determine the GSSG content, we used the following equation: GSSG $=A-B$; where $A$ is the total glutathione and $B$ is the GSH content. The protein carbonyl content was evaluated using the method of Levine et al. ${ }^{(16)}$.

\section{RNA extraction and real-time quantitative PCR}

PBMC RNA isolation was performed by an RNeasy Micro Kit (Qiagen, Barcelona, Spain), and the extracted RNA was treated with DNase (RNase-free DNase Set; Qiagen). For first-strand complementary DNA synthesis, a constant amount of $1 \mu \mathrm{g}$ total RNA was reverse-transcribed using random hexamers as primers and using Transcriptor Reverse Transcriptase (Roche, Mannheim, Germany). Gene mRNA levels were assessed by real-time PCR using an ABI Prism 7000 Sequence Detection System (Applied Biosystems, Darmstadt, Germany), using TaqMan technology. The reaction was performed, following the manufacturer's protocol, in a final volume of $25 \mu \mathrm{l}$. The cycle programme consisted of an initial denaturing of $10 \mathrm{~min}$ at 
$95^{\circ} \mathrm{C}$, then forty cycles of $15 \mathrm{~s}$ denaturing phase at $95^{\circ} \mathrm{C}$, and $1 \mathrm{~min}$ annealing and extension phase at $60^{\circ} \mathrm{C}$. The commercially available and prevalidated TaqMan primer/ probe sets used were as follows: glyceraldehyde 3-phosphate dehydrogenase (4326317E, RefSeq. NM_002046.3, used as an endogenous control for the target gene in each reaction), FASN (Hs01005622_m1, RefSeq. NM_004104.4), SREBP1 (Hs01088691_m1, RefSeq. NM_004176.3 and NM_001005291.1), $R X R \alpha$ (Hs01067634_m1, RefSeq. NM_00 2957.4), LXR $\alpha$ (Hs00172885_m1, RefSeq. NM_001130102.1, NM_001130101.1 and NM_005693.2), stearoyl-coenzyme A desaturase (SCD1; Hs01682761_m1, RefSeq. NM_005063.4) and FA transport protein 1 (FATP1; Hs01587917_m1, RefSeq. NM_198580.1). A threshold cycle $\left(C_{t}\right)$ value was obtained for each amplification curve, and a $\Delta C_{\mathrm{t}}$ value was first calculated by subtracting the $C_{\mathrm{t}}$ value for human glyceraldehyde 3-phosphate dehydrogenase complementary DNA from the $C_{\mathrm{t}}$ value for each sample and transcript.

Fold changes compared with the endogenous control were then determined by calculating $2^{-\Delta C_{\mathrm{t}}}$, and the expression results are given as the expression ratio relative to glyceraldehyde 3-phosphate dehydrogenase gene expression, according to the manufacturer's guidelines. All the samples were quantified in duplicate, and positive and negative controls were included in all the reactions.

\section{Statistical analysis}

Data are expressed as means and standard deviations. Comparisons between experimental conditions (baseline $v$. post-fat overload) were made using the Wilcoxon text for paired samples. The Pearson (Spearman) correlations were made between study variables to evaluate their association. Values were considered to be statistically significant when $P<0.05$ for two-tailed analysis. The analyses were performed using SPSS (version 15.0 for Windows; SPSS Iberica, Madrid, Spain).

\section{Results}

The anthropometric and biochemical variables of the study subjects and mRNA levels in the baseline and postprandial states are summarised in Table 1. After the fat overload, there was an increase in the plasma concentration of TAG, lipoperoxides, protein carbonyls and NEFA and in the mRNA levels of $L X R \alpha, R X R \alpha$ and SREBP1.

The correlation studies showed that both the baseline and postprandial plasma TAG levels correlated positively with insulin levels and with the mRNA levels of SREBP1 and FASN after the fat overload $(r \quad 0.595$ and 0.592; $P<0.05$, respectively, baseline; Fig. 1(a)) and $(r 0.528$ and $0.554 ; P<0.001$, respectively, postprandial; Fig. 1(b)). Likewise, baseline plasma NEFA concentrations correlated positively with FASN and SREBP1 following the fat overload ( $r 0.868$ and $0.797 ; P<0.05$, respectively; Fig. 1(c)).
Table 1. Effects of the fat overload in the study variablest (Mean values and standard deviations)

\begin{tabular}{|c|c|c|c|c|}
\hline & \multicolumn{2}{|c|}{ Baseline } & \multicolumn{2}{|c|}{ Postprandial } \\
\hline & Mean & SD & Mean & SD \\
\hline BMI $\left(\mathrm{kg} / \mathrm{m}^{2}\right)$ & $26 \cdot 58$ & $2 \cdot 86$ & & \\
\hline Waist:hip ratio & 0.91 & 0.08 & & \\
\hline Cholesterol (mmol/l) & $6 \cdot 07$ & $1 \cdot 15$ & $6 \cdot 07$ & $1 \cdot 13$ \\
\hline TAG $(\mathrm{mg} / \mathrm{l})^{*}$ & $3336 \cdot 3$ & $2672 \cdot 7$ & 4454.5 & $3100 \cdot 0$ \\
\hline CRP (mg/l) & 3.49 & $2 \cdot 71$ & 3.49 & $2 \cdot 78$ \\
\hline $\operatorname{NEFA}(\mathrm{nmol} / \mathrm{l})^{\star}$ & 0.73 & 0.29 & $1 \cdot 24$ & 0.71 \\
\hline Protein carbonyls $(\mathrm{nmol} / \mathrm{l})^{*}$ & $12 \cdot 60$ & $2 \cdot 68$ & $18 \cdot 36$ & $6 \cdot 14$ \\
\hline Lipoperoxides (nmol/l)* & $1237 \cdot 67$ & $743 \cdot 80$ & $1400 \cdot 50$ & $692 \cdot 12$ \\
\hline Total glutathione $(\mathrm{nmol} / \mathrm{l})^{*}$ & $573 \cdot 8$ & $83 \cdot 1$ & 601.4 & $69 \cdot 5$ \\
\hline GSSG $(\mathrm{nmol} / \mathrm{l})^{\star}$ & $280 \cdot 8$ & $70 \cdot 5$ & 244.5 & $58 \cdot 7$ \\
\hline $\mathrm{GSH}(\mathrm{nmol} / \mathrm{l})^{*}$ & $331 \cdot 1$ & 104.9 & $436 \cdot 4$ & $153 \cdot 9$ \\
\hline apo Al (mg/l) & $1615 \cdot 8$ & $332 \cdot 4$ & $1593 \cdot 1$ & $340 \cdot 0$ \\
\hline apo B (mg/l) & $1476 \cdot 2$ & $269 \cdot 4$ & $1479 \cdot 1$ & $273 \cdot 7$ \\
\hline FASN expression $\ddagger$ & $0 \cdot 14$ & 0.06 & 0.15 & $0 \cdot 11$ \\
\hline SCD1 expression $\ddagger$ & 0.02 & 0.01 & 0.03 & 0.02 \\
\hline FATP1 expression $\ddagger$ & 0.26 & $0 \cdot 21$ & 0.36 & 0.45 \\
\hline$L X R \alpha$ expression* $\ddagger$ & 0.03 & 0.02 & 0.04 & 0.03 \\
\hline$R X R \alpha$ expression* $\ddagger$ & 0.52 & 0.20 & 0.61 & 0.28 \\
\hline SREBP1 expression* $\ddagger$ & 0.17 & 0.08 & 0.21 & 0.15 \\
\hline
\end{tabular}

CRP, C-reactive protein; FASN, fatty acid synthase; $S C D 1$, stearoyl-CoA desaturase; FATP1, fatty acid transport protein; $L X R \alpha$, liver $\mathrm{X}$ receptor; $R X R \alpha$, retinoid $\mathrm{X}$ receptor; $S R E B P 1$, sterol regulatory element binding proteins.

* Mean values were significantly different $(P<0.05)$.

$\dagger$ Intra-group comparison of means before and after the fat overload.

$\ddagger$ Expression-level results are expressed as the expression ratio relative to glyceraldehyde 3 -phosphate dehydrogenase gene expression by calculating $2^{-\Delta C_{t}}$ according to the manufacturer's guidelines.

In addition, the up-regulated genes $(L X R \alpha, R X R \alpha$ and $S R E B P 1)$ correlated positively with lipogenic genes in peripheral cells (Fig. 2). $R X R \alpha$ mRNA levels correlated directly with SREBP1 at baseline $(r 0.574 ; P<0.05$; Fig. 2(a)) and postprandially $(r 0.839$; $P<0.01$; Fig. 2(b)). FASN mRNA levels correlated positively with $R X R \alpha$ and SREBP1 at baseline $(r \quad 0.594$ and 0.632 , respectively; $P<0.05$; Fig. 2(c)), and postprandial FASN mRNA levels correlated with the postprandial mRNA levels of SREBP1 and RXR $\alpha$ (r 0.838 and 0.781 , respectively, $P<0.01$; Fig. 2(d)). Finally, the correlation of FASN mRNA levels with SCD1 mRNA levels at baseline was positive too ( $r$ 0.426; $P<0 \cdot 05$; Fig. 2(e)).

Baseline $L X R \alpha$ mRNA levels showed a direct correlation with biomarkers of oxidative stress (Table 2), i.e. baseline plasma lipoperoxide levels $(r 0.902 ; P<0.001)$, as well as with baseline GSH $(r 0.612 ; P<0.05)$ and baseline GSH with postprandial $L X R \alpha(r 0.783 ; P<0.05)$. Baseline $R X R \alpha$ correlated with postprandial GSH $(r 0.632 ; P<0.05)$.

\section{Discussion}

In the present study, we show for the first time that, in PBMC, a fat overload can lead to an increase (upregulation) in the mRNA levels of nuclear regulators such as $L X R \alpha, R X R \alpha$ and $S R E B P 1$, which are related to cell lipogenic capacity.

The type of dietary FA influences the levels of plasma lipoproteins. The down-regulation or up-regulation of 

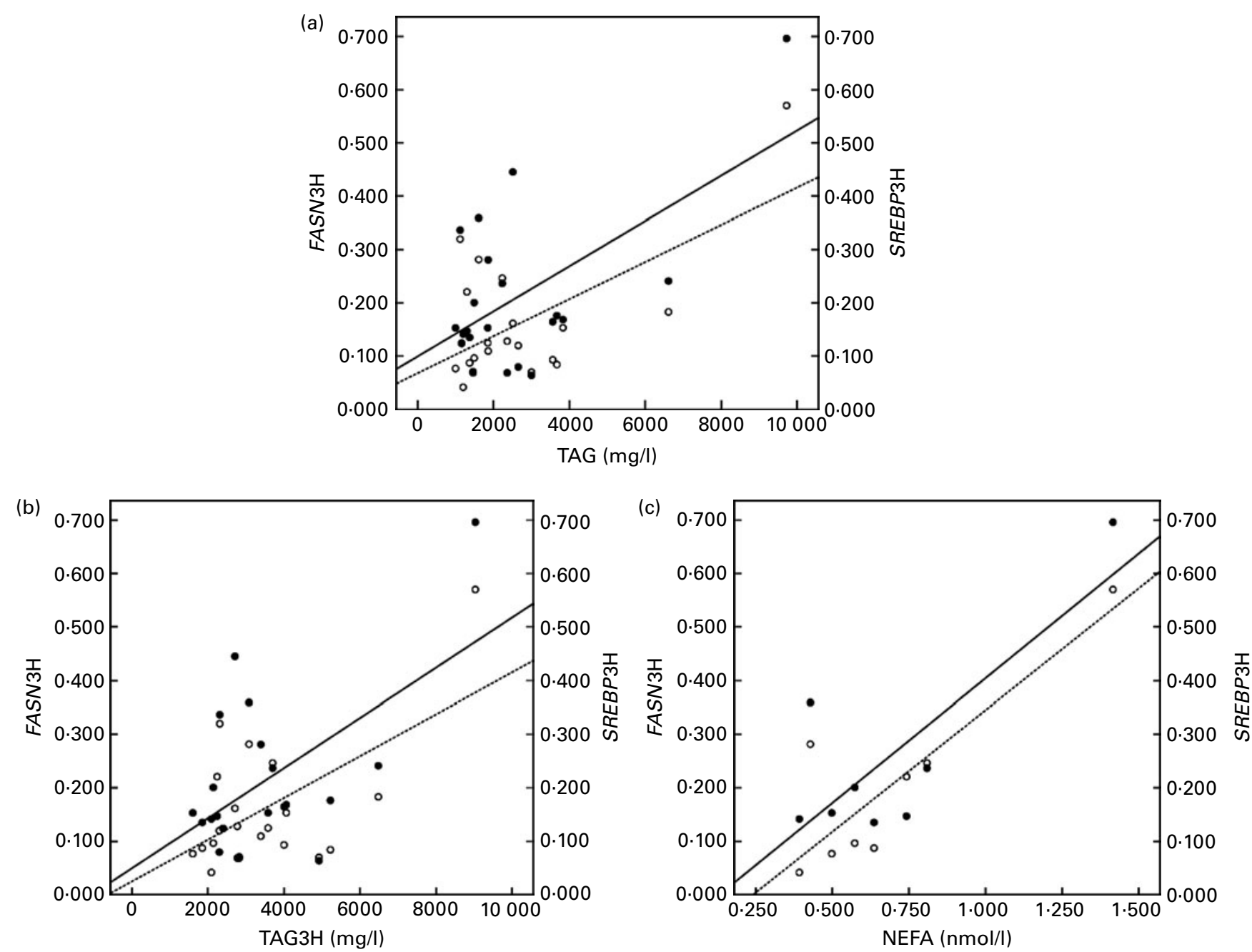

Fig. 1. Linear relationship determined by Pearson's correlation coefficient test between (a) TAG at the baseline state and fatty acid synthase (FASM) mRNA levels $(\mathrm{O}--)$ and sterol regulatory element binding protein (SREBP) mRNA levels $(-)$ at the postprandial state $(3 \mathrm{~h}$ later) $(F A S N 3 \mathrm{H}$ and $S R E B P 13 \mathrm{H}$, respectively); FASN3H $r 0.595$ and SREBP1 $r$ 0.592; $P<0.05$, (b) TAG at the postprandial state ( $3 \mathrm{~h}$ later) and FASN mRNA levels $(O--)$ and $S R E B P$ mRNA levels $(\bullet-)$ at the postprandial state ( $3 \mathrm{~h}$ later) (FASN3H and SREBP13H, respectively); $F A S N \quad 0.628$ and SREBP1 $r 0.554 ; P<0.001$, (c) NEFA at the baseline state and FASN mRNA levels $\left(\mathrm{O}_{--}\right)$and SREBP mRNA levels $(-)$at the postprandial state $(3 \mathrm{~h}$ later) (FASN3H and SREBP13H, respectively); FASN3H $r 0.868$ and SREBP1 $r 0.797 ; P<0.05$. mRNA-level results are expressed as the expression ratio relative to glyceraldehyde 3-phosphate dehydrogenase gene expression by calculating $2^{-\Delta C}$, according to the manufacturer's guidelines.

genes also depends on the degree of FA saturation ${ }^{(17)}$. In the present study, the fat overload contained a high proportion of MUFA and a low percentage of PUFA, mainly $n$-9, which explains the up-regulation of the FA target nuclear factors SREBP, RXR $\alpha$ and $L X R \alpha$.

The association has been reported between an elevated postprandial TAG response to a fat overload and a greater risk for CVD and the metabolic syndrome ${ }^{(1)}$, greater inflammation, higher oxidative stress and more cardiovascular events ${ }^{(18)}$. Some years ago, our group described the genetic influence of certain apo polymorphisms on postprandial hypertriacylglycerolaemia, as well as the association between an increase in oxidative stress and plasma TAG levels in response to a fat overload ${ }^{(18,19)}$. In the present study, we again show that a fat overload also increases the markers of oxidative stress such as glutathione, lipoperoxide and protein carbonyl levels. We have also studied the genetic expression of genes related to postprandial lipid metabolism, and a fat overload has been reported to be able to modify PPAR $\gamma$ expression in metabolic syndrome patients ${ }^{(20)}$. In the same way, the fat overload alters the mRNA levels of certain regulatory factors of lipid metabolism in peripheral cells.

As we have seen earlier, SREBP enhance the expression of lipogenic genes ${ }^{(\mathcal{9}, 21)}$ and are implicated in the pathophysiological development of obesity, type 2 diabetes mellitus, dyslipidaemia, atherosclerosis and the metabolic syndrome. SREBP gene expression is lower in adipose tissue from obese and type 2 diabetes mellitus patients ${ }^{(8,22,23)}$. In addition, animal models have shown that the processes of fasting and re-feeding produce an increased expression of lipogenic genes in liver cells, white adipose tissue and skeletal muscle, with a fall in SREBP1 at fasting and an increase after the intake of a carbohydrate-rich diet ${ }^{(24)}$. 

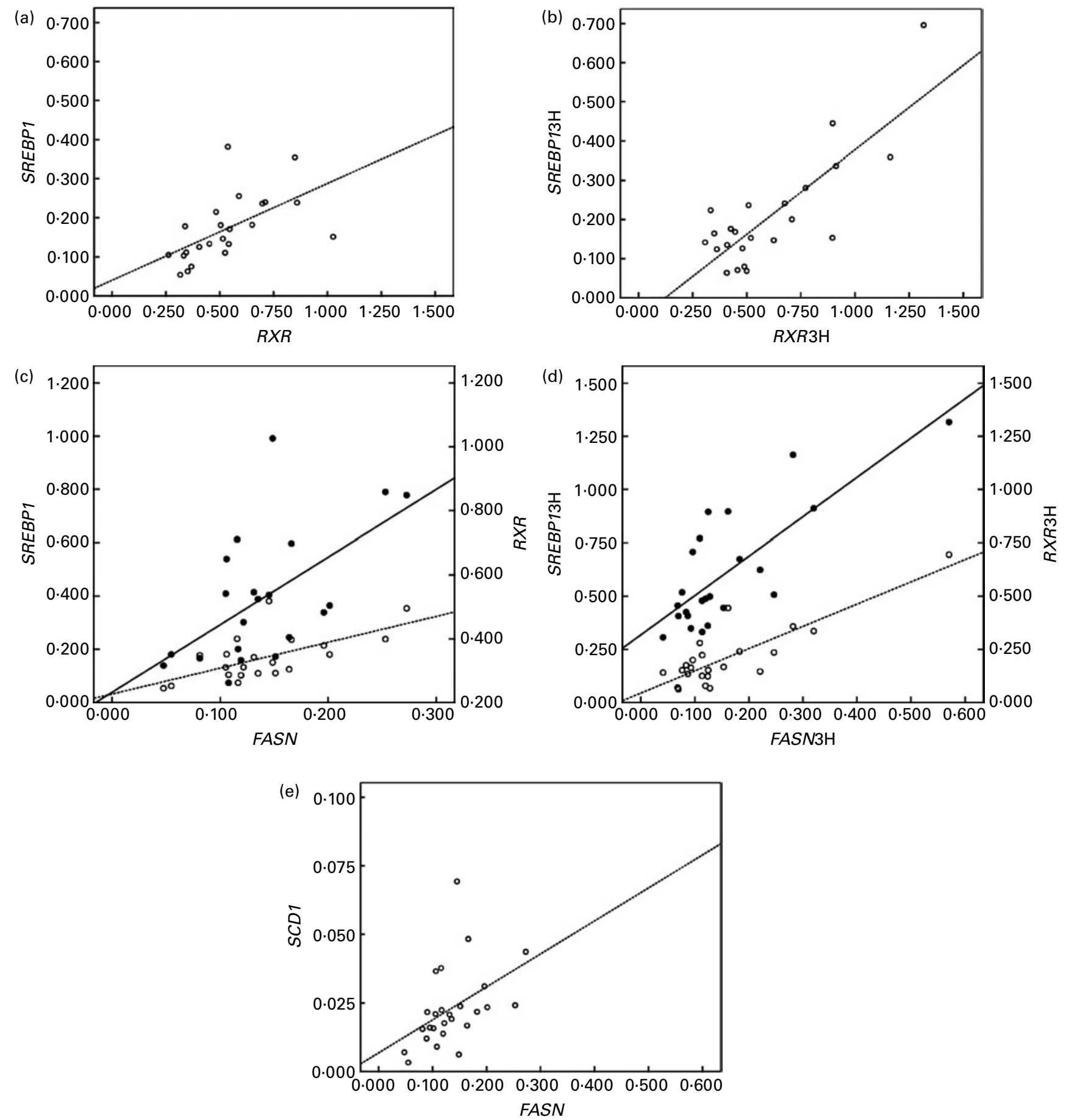

Fig. 2. Linear relationship determined by Pearson's correlation coefficient test between (a) retinoid $X$ receptor $(R X R)$ mRNA levels and sterol regulatory element binding protein (SREBP) mRNA levels $(O--)$ at the baseline state $(R X R \alpha$ and $S R E B P 1$, respectively); $r 0.574 ; P<0.01$, (b) RXR mRNA levels and SREBP mRNA levels $\left(\mathrm{O}_{--}\right)$at the postprandial state (3h later) $(R X R \alpha 3 \mathrm{H}$ and $S R E B P 13 \mathrm{H}$, respectively); $r 0.839 ; P<0.01$, (c) fatty acid synthase (FASN) mRNA levels and SREBP mRNA levels $\left(\mathrm{O}_{--}\right)$and $R X R$ at the baseline state (FASN, SREBP1 and RXR $\alpha$, respectively); SREBP1 $r 0.632$ and $R X R \quad r 0.594 ; P<0.05$, (d) FASN mRNA levels and SREBP mRNA levels $\left(\mathrm{O}_{--}\right)$and $R X R(\bullet-)$ at the postprandial state ( $3 \mathrm{~h}$ later) $(F A S N 3 \mathrm{H}$, SREBP13H and RXR $3 \mathrm{H}$, respectively); SREBP13H $r 0.838$ and RXR3H $r 0.781 ; P<0.01$, (e) FASN mRNA levels and stearoyl-coenzyme A desaturase mRNA levels $(O--)$ at the baseline state (FASN and SREBP1, respectively) $r 0.426 ; P<0.05$. mRNA-level results are expressed as the expression ratio relative to glyceraldehyde 3-phosphate dehydrogenase gene expression by calculating $2^{-\Delta G}$, according to the manufacturer's guidelines.

In the present study, the fat overload produced an increase in SREBP1 after its intake, probably due to the increase in dietary FA and the interconnection between lipid and carbohydrate metabolism.
$R X R$, when its $R X R \alpha$ function is altered, modifies the PPAR $\alpha$ pathways, leading to alteration of the differentiation of preadipocytes in adipose tissue, producing obesity ${ }^{(25)}$. In animal models, the loss of $R X R \alpha$ function causes, at 
Table 2. Correlations between lipogenic regulators and oxidative stress biomarkers

\begin{tabular}{lccc}
\hline & Lipoperoxide & GSH & GSH3H \\
\hline$L X R \alpha$ & $0.902^{\star *}$ & $0.612^{*}$ & $-\dagger$ \\
$L X R \alpha 3 \mathrm{H}$ & $-\dagger$ & $0.783^{*}$ & $-\dagger$ \\
$R X R \alpha$ & $-\dagger$ & $-\dagger$ & $0.632^{*}$
\end{tabular}

GSH3H, GSH $3 \mathrm{~h} ; L X R \alpha$, liver $\mathrm{X}$ receptor; $L X R \alpha 3 \mathrm{H}$, liver $\mathrm{X}$ receptor $3 \mathrm{~h} ; R X R \alpha$, retinoid $\mathrm{X}$ receptor. ${ }^{\star} P<0.01,{ }^{\star \star} P<0.05$.

$\dagger$ No significant correlations.

the tissue level, alteration of $P P A R \alpha$ pathways, for example FA oxidation. Reactive agents activate genes related to desaturation, such as SCD1 in muscle tissue. The present study shows that after the fat overload, there is a rise in $R X R$ mRNA levels in peripheral cells due to an increase in FA activators of this regulatory element. In contrast, we detected no increase in SCD1 mRNA levels, probably because $R X R$ activation enhances other specific pathways of these cells, such as the immune response or oxidative stress increase. In the present study, we observed a significant increase in $L X R$ mRNA levels after the fat overload.

$L X R$ seems to regulate $S R E B P$ expression in hepatic and adipose tissues $^{(12,26,27)}$, which intervenes in the expression of enzymes involved in FA and TAG synthesis, such as FASN or SCD1. $L X R$ binds directly to the SREBP promoter and activates FASN expression ${ }^{(28)}$. This is corroborated by in vivo models and in animal models without $L X R$, which have a reduced baseline SREBP, FASN and SCD1 expression $^{(12,29)}$. $L X R$ is another nuclear receptor that forms heterodimers with $R X R^{(30)} . R X R / L X R$ plays a relevant role in $S R E B P$ transcription activation mediated by insulin: insulin activates the $S R E B P$ promoter, leading to an increase in $R X R / L X R$ transcriptional activity ${ }^{(31)}$. In addition, the $P P A R / R X R$ and $L X R / R X R$ heterodimers have a sensor action for dietary lipids in peripheral cells ${ }^{(32)}$, acting in cholesterol and NEFA homeostasis, with an important role in inflammation and atherosclerosis. Our data show that, after the fat overload, there is an increase in $L X R \alpha$ accompanied by an increase in $R X R$ and SREBP mRNA levels, which confirms this hypothesis; moreover, this $L X R \alpha$ increase was associated with higher oxidative stress in the cells studied.

As we have seen earlier, SREBP, RXR and $L X R$ are involved in inflammation/oxidative stress processes ${ }^{(33)}$, and the present results corroborate it showing the correlations positively between $R X R$ and $L X R$ mRNA levels and the markers of oxidative stress such as lipoperoxides and GSH, even after a fat overload.

Therefore, the main new finding is that these increases in nuclear regulator gene expression related to cell lipogenic capacity take place in peripheral cells in response to a stimulus, in this case a fat overload. In view of the results, we are aware that, although there are certain limitations in using these cells instead of adipose or hepatic tissue (hard to access), our data with PBMC corroborate previous results, even in animal models. Thus, the cellular response to an external TAG and FA increase may translate into an increased genetic expression of those genes directly implied in lipid metabolism. Our data allow the study of these pathways in peripheral cells, a much more accessible model than other tissues.

\section{Acknowledgements}

The present study was supported by the Instituto de Salud Carlos III (PS09/00997, PI081655 and CP07/0095) and Consejería de Innovación, Ciencia y Empresa (PI 325/08). There are no conflicts of interest. M. D. M. participated in drafting the manuscript, the genetic studies and in performing the statistical analysis. M. I. Q.-O. and M. C.-P. participated in the analysis of biochemical variables and in the statistical analysis. M. M. and R. E. B. were scientific advisers. F. J. T. and F. C. designed the research and participated in performing the statistical analysis. F. J. T. obtained the anthropometrical characteristics and the written consent of patients. F. C. and M. D. M. wrote the paper, and $\mathrm{F}$. C. had primary responsibility for the final content.

\section{References}

1. Fujioka Y \& Ishikawa Y (2009) Remnant lipoproteins as strong key particles to atherogenesis. J Atheroscler Thromb 16, $145-154$

2. Bell DS, O'Keefe JH \& Jellinger P (2008) Postprandial dysmetabolism: the missing link between diabetes and cardiovascular events? Endocr Pract 14, 112-124.

3. Le NA \& Walter MF (2007) The role of hypertriglyceridemia in atherosclerosis. Curr Atheroscler Rep 9, 110-115.

4. Cohn JS (2006) Postprandial lipemia and remnant lipoproteins. Clin Lab Med 26, 773-786.

5. Collino M, Patel NS \& Thiemermann C (2008) PPARs as new therapeutic targets for the treatment of cerebral ischemia/ reperfusion injury. Ther Adv Cardiovasc Dis 2, 179-197.

6. Hernández-Vallejo SJ, Alqub M, Luquet S, et al. (2009) Shortterm adaptation of postprandial lipoprotein secretion and intestinal gene expression to a high-fat diet. Am J Physiol Gastrointest Liver Physiol 296, G782-G792.

7. Eberle D, Hegarty B, Bossard P, et al. (2004) SREBP transcription factors: master regulators of lipid homeostasis. Biochimie 86, 839-848.

8. Kolehmainen M, Vidal H, Alhava E, et al. (2001) Sterol regulatory element binding protein-1c (SREBP-1c) expression in human obesity. Obes Res 9, 706-712.

9. Magana MM, Koo SH, Towle HC, et al. (2000) Different sterol regulatory element-binding protein-1 isoforms utilize distinct co-regulatory factors to activate the promoter for fatty acid synthase. J Biol Chem 275, 4726-4733.

10. Bełtowski J (2008) Liver X receptors (LXR) as therapeutic targets in dyslipidemia. Cardiovas Ther 26, 297-316.

11. Yoshikawa T, Shimano H, Yahagi N, et al. (2002) Polyunsaturated fatty acids suppress sterol regulatory element-binding protein $1 \mathrm{c}$ promoter activity by inhibition of liver $\mathrm{X}$ receptor (LXR) binding to LXR response elements. $J$ Biol Chem 277, 1705-1711.

12. Repa JJ, Liang G, Ou J, et al. (2000) Regulation of mouse sterol regulatory element-binding protein-1c gene 
(SREBP-1c) by oxysterol receptors, LXR $\alpha$ and LXR $\beta$. Genes Dev 14, 2819-2830.

13. Lalloyer F, Pedersen TA, Gross B, et al. (2009) Rexinoid bexarotene modulates triglyceride but not cholesterol metabolism via gene-specific permissivity of the RXR/LXR heterodimer in the liver. Arterioscler Thromb Vasc Biol 29, 1488-1495.

14. Expert Panel on Detection, Evaluation, and Treatment of High Blood Cholesterol in Adults (2001) Executive Summary of The Third Report of The National Cholesterol Education Program (NCEP) Expert Panel on Detection, Evaluation, And Treatment of High Blood Cholesterol In Adults (Adult Treatment Panel III). JAMA 285, 2486-2497.

15. Grundy SM (2004) Obesity, metabolic syndrome, and cardiovascular disease. J Clin Endocrinol Metab 89, 2595-2600.

16. Levine RL, Garland D, Oliver CN, et al. (1990) Determination of carbonyl content in oxidatively modified proteins. Methods Enzymol 186, 464-478.

17. Clarke SD, Baillie R, Jump DB, et al. (1997) Fatty acid regulation of gene expression. Its role in fuel partitioning and insulin resitance. Ann N Y Acad Sci 827, 178-187.

18. Cardona F, Túnez I, Tasset I, et al. (2008) Fat overload aggravates oxidative stress in patients with the metabolic syndrome. Eur J Clin Invest 38, 510-515.

19. Macias-Gonzalez M, Cardona F, Queipo-Ortuño $\mathrm{M}$, et al. (2008) PPAR $\gamma$ mRNA expression is reduced in PBMC after fat overload in patients with metabolic syndrome. J Nutr 138, 903-907.

20. Cardona F, Tunez I, Tasset I, et al. (2008) Similar increase in oxidative stress after fat overload in persons with baseline hypertriglyceridemia with or without the metabolic syndrome. Clin Biochem 41, 701-705.

21. Shimomura I, Matsuda M, Hammer RE, et al. (2000) Decreased IRS-2 and increased SREBP-1c lead to mixed insulin resistance and sensitivity in livers of lipodystrophic and ob/ob mice. Mol Cell 6, 77-86.

22. Sewter C, Berger D, Considine RV, et al. (2002) Human obesity and type 2 diabetes are associated with alterations in SREBP1 isoform expression that are reproduced ex vivo by tumor necrosis factor-alpha. Diabetes 51, 1035-1041.
23. Diraison F, Dusserre E, Vidal H, et al. (2002) Increased hepatic lipogenesis but decreased expression of lipogenic gene in adipose tissue in human obesity. Am J Physiol Endocrinol Metab 282, E46-E51.

24. Eberlé D, Hegarty B, Bossard P, et al. (2004) SREBP transcription factors: master regulators of lipid homeostasis. Biochimie 86, 839-848.

25. Imai T, Jiang M, Chambon $\mathrm{P}$, et al. (2001) Impaired adipogenesis and lipolysis in the mouse upon selective ablation of the retinoid $\mathrm{X}$ receptor alpha mediated by a tamoxifeninducible chimeric Cre recombinase (Cre-ERT2) in adipocytes. Proc Natl Acad Sci U S A 98, 224-228.

26. Laffitte BA, Chao LC, Li J, et al. (2003) Activation of liver X receptor improves glucose tolerance through coordinate regulation of glucose metabolism in liver and adipose tissue. Proc Natl Acad Sci US A 100, 5419-5424.

27. Muscat GE, Wagner BL, Hou J, et al. (2002) Regulation of cholesterol homeostasis and lipid metabolism in skeletal muscle by liver X receptors. J Biol Chem 277, 40722-40728.

28. Ferré P \& Foufelle F (2007) SREBP-1c transcription factor and lipid homeostasis: clinical perspective. Horm Res 68, 72-82.

29. Peet DJ, Turley SD, Ma W, et al. (1998) Cholesterol and bile acid metabolism are impaired in mice lacking the nuclear oxysterol receptor LXR alpha. Cell 93, 693-704.

30. Hamada K, Gleason SL, Levi BZ, et al. (1989) H-2RIIBP, a member of the nuclear hormone receptor superfamily that binds to both the regulatory element of major histocompatibility class I genes and the estrogen response element. Proc Natl Acad Sci U S A 86, 8289-8293.

31. Chen G, Liang G, Ou J, et al. (2004) Central role for liver X receptor in insulin-mediated activation of Srebp-1c transcription and stimulation of fatty acid synthesis in liver. Proc Natl Acad Sci U S A 101, 11245-11250.

32. Ricote M, Valledor AF \& Glass CK (2004) Decoding transcriptional programs regulated by PPARs and LXRs in the macrophage: effects on lipid homeostasis, inflammation, and atherosclerosis. Arterioscler Thromb Vasc Biol 24, 230-239.

33. Sugden MC \& Holness MJ (2008) Role of nuclear receptors in the modulation of insulin secretion in lipid induced insulin resistance. Biochem Soc Trans 36, 891-900. 